\title{
A Psychiatric Presentation of Wernicke's Encephalopathy Following Intravenous Fluid Administration
}

\author{
Douglas Geenans, D.O. \\ McLean Hospital, Belmont, Massachusetts
}

Follow this and additional works at: https://jdc.jefferson.edu/jeffjpsychiatry

Part of the Psychiatry Commons

Let us know how access to this document benefits you

\section{Recommended Citation}

Geenans, D.O., Douglas (1992) "A Psychiatric Presentation of Wernicke's Encephalopathy Following Intravenous Fluid Administration," Jefferson Journal of Psychiatry. Vol. 10 : Iss. 2 , Article 5.

DOI: https://doi.org/10.29046/JJP.010.2.003

Available at: https://jdc.jefferson.edu/jeffjpsychiatry/vol10/iss2/5

This Article is brought to you for free and open access by the Jefferson Digital Commons. The Jefferson Digital Commons is a service of Thomas Jefferson University's Center for Teaching and Learning (CTL). The Commons is a showcase for Jefferson books and journals, peer-reviewed scholarly publications, unique historical collections from the University archives, and teaching tools. The Jefferson Digital Commons allows researchers and interested readers anywhere in the world to learn about and keep up to date with Jefferson scholarship. This article has been accepted for inclusion in Jefferson Journal of Psychiatry by an authorized administrator of the Jefferson Digital Commons. For more information, please contact: JeffersonDigitalCommons@jefferson.edu. 


\title{
A Psychiatric Presentation of Wernicke's Encephalopathy Following Intravenous Fluid Administration
}

\author{
Douglas Geenans, D.O.
}

\begin{abstract}
Psychiatrists are frequently challenged to differentiate primary psychiatric symptoms from those that arise secondary to medical illness. Errors in clinical assessment can lead to significant morbidity and even mortality. Wernicke's encephalopathy is a medical condition that presents, in part, as psychiatric symptomatology. Despite an estimated incidence of $2 \%, 80 \%$ of the cases are undiagnosed. Of its classic triad, ophthalmoplegia and ataxia can be quite subtle, or even absent, whereas mental status changes are present in all but $10 \%$ of cases. This disorder, although widely recognized as a complication of alcoholism, has many less frequently considered etiologies, including iatrogenic causes, which may constitute a large fraction of the unrecognized cases. The author looks at a case of Wernicke's encephalopathy that was iatrogenically induced and presented as psychiatric symptomatology.

Wernicke's encephalopathy is a medical condition which results from impaired intestinal absorption of thiamine. Its primary manifestations are neurological and psychiatric, however its neurological sequelae (ophthalmoplegia and ataxia) are often subtle and a high index of suspicion is essential to consider the diagnosis (1). Disturbances of consciousness and mentation are typical and present in all but 10 percent of patients (2). The following case illustrates a primarily psychiatric presentation of the illness, following intravenous fluid administration, in a 31-year-old man with hyperemesis and protracted hiccups.
\end{abstract}

\section{CASE REPORT}

The patient, a 31-year-old man, presented to the emergency room with a chief complaint of intractable hiccups which had progressed to protracted vomiting, resulting in a 15 pound weight loss over two weeks. Physical and laboratory examination on admission revealed a moderately dehydrated man with no abnormalities in his mental state. He admitted to history of alcohol use but claimed to have been sober for one year.

He was admitted to the hospital and hydrated with two liters of D5 1/2 NS. Fourteen hours after admission, he became more agitated and complained of "little fuzzy things" crawling on his skin. As he became more disorganized and confused, soft restraints were used to control his activity. Benzodiazepines and low-dose antipsychotics were employed in an attempt to control his hallucinations with no effect. At that time, psychiatric consultation was requested. 
The patient was found to be actively hallucinating with both visual and tactile hallucinations. He was confused, disoriented, and actively confabulating. His speech was dysarthric. His irritability and agitation made a physical examination quite difficult. Vital signs were within normal limits and stat $\mathrm{CBC}$, urine drug screen, and blood chemistry profile were within normal limits. Further cognitive evaluation was impossible given his disorganized state.

Given the prominent visual and tactile hallucinations, an organic factor was sought. A temporal relationship was established between medical intervention and the onset of symptoms. A more thorough examination of his eyes was performed revealing subtle weakness of the lateral recti bilaterally. Since he had been in restraints for two days, ataxia had not been noted by the attending staff, however when assisted in ambulation, he was found to be markedly ataxic.

Based on these findings, a diagnosis of Wernicke's encephalopathy was made and thiamine, 100 mgs. IV was started daily. After three days, the patient became lucid and baseline mental state was reestablished. The only residual was his dysarthric speech which was later identified as an early symptom of Amyotrophic Lateral Sclerosis.

\section{DISCUSSION}

Historically, Wernicke first described "polioencephalitis hemorrhagica superioris" encephalopathy in three patients. Two were alcoholics and one was a young woman with persistent vomiting following the ingestion of sulfuric acid. Since that time, Wernicke's encephalopathy has been most commonly described with alcoholism, but it can be associated with any condition that affects intestinal absorption of thiamine, i.e., prolonged starvation (4), hyperemesis gravidarum (5), gastroplasty (6), and diarrhea (7). These less commonly identified etiologies may constitute a large fraction of the unrecognized cases (8). In 1974, Ebels reported 22 unexpected autopsy cases of Wernicke's encephalopathy; alcohol was a causative factor in only four (9).

In addition to the previously mentioned etiologies, iatrogenic causes arise from parenteral alimentation and fluid administration without vitamin supplementation (10). During normal carbohydrate metabolism, thiamine is consumed as an enzymatic cofactor for transketolase in the pentose phosphate pathway and for pyruvate decarboxylase and alpha ketoglutarate in the tricarboxylic acid cycle (12). When a large or concentrated glucose bolus is administered to the malnourished, asymptomatic patient, thiamine stores in the brain are rapidly exhausted, aerobic glycolysis is subsequently inhibited, and nervous tissue dysfunction occurs manifesting as the symptoms of Wernicke's encephalopathy (11).

Although Wernicke's encephalopathy is classically described as the triad of ophthalmoplegia, ataxia, and mental confusion, any one of these symptoms may be the initial manifestation (2). This "classic triad" however, is frequently not obvious. Many patients may exhibit only partial findings and some may have none. Harper reviewed the clinical records of 131 cases of Wernicke's encephalopathy diagnosed at autopsy, and found that only $16 \%$ of patients had the classic triad and $19 \%$ had no documented clinical signs (8). The ocular manifestations-nystagmus, and weakness or paralysis of the external rectus muscles, or of conjugate gaze-are most useful in making a definitive diagnosis (2). But these symptoms can be subtle and easily 
missed, especially if the patient is so cognitively impaired that they cannot cooperate with the examination. In addition, ataxia, in its mildest form, can easily be missed and only demonstrated by tandem walking (2).

Mental disturbances may be the most useful in increasing the clinician's suspicion, as they are present in all but $10 \%$ of patients (2). The most common derangement is global confusion manifested by disorientation, misidentification of those around the patient, and difficulty in grasping the meaning of the immediate situation (2). About $15 \%$ of patients show signs of alcohol withdrawal, i.e., hallucinations and other disorders of perception (2).

Rapid assessment and correction of Wernicke's encephalopathy is imperative as it is considered a medical emergency, where delays in treatment contribute to a $10-20 \%$ mortality rate (2). To this end, a high index of suspicion must always be present when faced with a patient who presents with a sudden change in mental status. Special emphasis must be placed on the context in which symptoms began. Does the patient have an alcohol history? Are the hallucinations typical of a functional psychosis (auditory) or are they more consistent with organicity (tactile and visual)? Try to establish a temporal relationship to medical intervention. Lastly, if psychopharmacologic interventions have been used unsuccessfully, consider other etiologies.

The goal of treatment in the acute phase of Wernicke's encephalopathy is to prevent Korsakoff's psychosis. Once this amnestic syndrome occurs, complete recovery is only $20 \%$. Of the remainder, some improve slightly and others remain in the need of total nursing care or progress to death (2).

\section{SUMMARY}

Despite clinicians' awareness of Wernicke's encephalopathy and its classic triad (ophthalmoplegia, ataxia, confusion), the diagnosis is made in only $20 \%$ of the cases. This may be a function of a subclinical, limited symptoms, or atypical presentations, or a lack of considering the diagnosis in the absence of alcoholism. Predisposing factors to Wernicke's encephalopathy include starvation, vomiting, diarrhea, and GI surgical procedures. Iatrogenic causes result from the replacement of fluids especially glucose in the absence of vitamin supplementation. Awareness of the various etiologies and the variety of presentations may contribute to clinicians' ability to make this elusive diagnosis.

\section{REFERENCES}

1. Turner S, Daniels L, Greer S: Wernicke's encephalopathy in an 18-year-old woman. Br J Psychiatry 1989; 154:261-2

2. Adams RA, Victor M: Principles of Neurology. McGraw Hill, 761-768, 1985

3. Tomasulo PA, Kater RMH, Iber FL: Impairment of thiamine absorption in alcoholism. Am J Clin Nutri 1968; 21:1341-4 
4. Drenick EJ, Joven CB, Swendseid ME, et al: Occurrence of acute Wernicke's encephalopathy during prolonged starvation for the treatment of obesity. N Eng J Med 1966; 274:937-939

5. Nightingale S, Bates P, Heath PD, et al: Wernicke's encephalopathy in hyperemesis gravidarum. Postgrad Med 1982; 58:558-9

6. Oczkowski WJ, Kertesz A: Wernicke's encephalopathy after gastroplasty for morbid obesity. Neurology 1985; 35(1):99-101

7. Epstein RS: Wernicke's encephalopathy following lithium induced diarrhea (letter). Am J Psychiatry $1989 ; 146: 806-7$

8. Harper C: The incidence of Wernicke's encephalopathy in Australia: A neuropathological study of 131 cases. J Neurology Neurosurg Psych 1983; 46:593-8

9. Ebels EJ: Underlying illness in Wernicke's encephalopathy: Analysis of possible causes of underdiagnosis. Eur Neurol 1974; 12:226-8

10. Nadel AM, Burger PC: Wernicke's encephalopathy following prolonged intravenous therapy. JAMA 1976; 235:2403-2405

11. Watson AJS, Walker JF, Tomkin GH, et al: Acute Wernicke's encephalopathy precipitated by glucose loading. Ir J Med Sci 1981; 150:301-3

12. Reuler JB, Girard DE, Cooney TC: Current concepts of Wernicke's encephalopathy. N Engl J Med 1985; 312:1035-9 